\title{
Importance of both innate immunity and acquired immunity for rapid expulsion of $S$. venezuelensis
}

\section{Koubun Yasuda, Makoto Matsumoto and Kenji Nakanishi *}

Department of Immunology and Medical Zoology, Hyogo College of Medicine, Nishinomiya, Japan

Edited by:

Kendall A. Smith, Weill Medical

College of Cornell University, USA

\section{Reviewed by:}

Lynn Soong, The University of Texas

Medical Branch, USA

Jieliang Li, Temple University, USA

*Correspondence:

Kenji Nakanishi, 1-1 Mukogawa-cho,

Nishinomiya, Hyogo, Japan

e-mail: nakaken@hyo-med.ac.jp
In the first part of this review, we described the relevant roles of endogenous IL-33 for accumulation of ILC2 and eosinophils even in the lungs of Rag2-I- mice. Type II alveolar epithelial (ATII) cells express IL-33 in their nucleus and infection with Strongyloides venezuelensis induces IL-33 production by increasing the number of ATII cells possibly by the action of chitin. IL-33 from ATII cells induces ILC2 proliferation and the same time activates them to produce IL-5 and IL-13, which in combination induce lung eosinophilic inflammation, aiding to expel infected worms in the lungs. In the second part, we showed that, although $\mathrm{AID}^{-1-}$ mice normally develop Th2 cells and intestinal mastocytosis after infection with $S$. venezuelensis, they need adoptive transfers of immune sera from $S$. venezuelensis infected mice to obtain the capacity to promptly expel $S$. venezuelensis. Thus, intestinal nematode infection induces various Th2 immune responses (e.g., Th2 cell, ILC2, goblet cell hyperplasia, intestinal mastocytosis, smooth muscle cell contraction, local and systemic eosinophilia, and high serum level of $\lg E$ and $\lg \mathrm{G} 1$ ). However, all of them are not necessary for rapid expulsion of intestinal nematodes. Instead, some combinations of Th2 immune responses are essentially required.

Keywords: intestinal nematode, Th2 cell, ILC2, IgE, mast cell, eosinophils, IL-33, chitin
When animals are infected with intestinal nematodes, resistant hosts develop Th2 immune responses, which induce IgG1 and IgE production, intestinal mastocytosis, pulmonary eosinophilia (e.g., Loeffler syndrome), and systemic eosinophilia. Nippostrongylus brasiliensis is a gut-dwelling nematode. Goblet cell hyperplasia and intestinal smooth muscle contraction, both of which are induced by the action of Th2 cytokines (IL- 4 and IL-13), are indispensable for rapid expulsion of $N$. brasiliensis $(1,2)$. However, B cells and antibody $(\mathrm{Ab})$ production are not needed for this expulsion (3). Thus, host animals expel $N$. brasiliensis in a T cell but not B cell-dependent manner.

Strongyloides venezuelensis, a counterpart of human pathogen Strongyloides stercoralis, naturally infects rodents and has been used as an experimental intestinal parasite model (4). In contrast to $N$. brasiliensis expulsion, intestinal mastocytosis is indispensable for rapid expulsion of $S$. venezuelensis (5-7). Furthermore, FcR $\gamma$-induced mucosal mast cell (MMC) activation is important for rapid expulsion of $S$. venezuelensis (8), suggesting that Abdependent MMC activation is essential for rapid expulsion of $S$. venezuelensis from intestine.

In the life cycle of $S$. venezuelensis, third stage larvae (L3) migrate to the lung, where they induce severe inflammatory change (mouse Loeffler syndrome), characterized by severe eosinophilic infiltration and goblet cell hyperplasia. Then, they leave lungs, migrate to oral cavity, and go down to small intestine, where they become adult worms and induce severe intestinal mastocytosis. Host animals try to expel them by the action of mast cells in intestine. Therefore, there are two inflammatory sites; one in the lung and the other in the intestine. We speculated that these two sites are important for protection against intestinal nematode. Here, we show the importance of innate immunity and acquired immunity for rapid expulsion of S. venezuelensis.

\section{IS LOEFFLER SYNDROME A PROTECTIVE IMMUNE RESPONSE?}

We first examined the mechanism how $S$. venezuelensis infection induces pulmonary eosinophilia. Loeffler syndrome is severe pulmonary eosinophilia, and parasite-infected patients often develop this syndrome (9). However, we still do not know why only lungs develop such severe eosinophilic inflammation after infection with intestinal nematodes, such as round worms, hook worms, and Strongyloides spp. (9). To understand this mechanism, we used S. venezuelensis infected-animal model. As intranasal administration of IL-33 induces severe pulmonary eosinophilia and goblet cell hyperplasia in the lungs of animals (10), we speculated that $S$. venezuelensis infection induces Loeffler syndrome in an IL-33-dependent manner (11).

IL-33 is a member of IL-1 family cytokine (12), stored in the nucleus of cells (13), released when cells are damaged (14), and binds to ST2 (IL-1RL1) on Th2 cells and various types of innate immune cells including mast cells, basophils, eosinophils, and group 2 innate lymphoid cells (ILC2s) (10, 15-19). In the first part of this review, we demonstrate that worms increase IL33 expression in the lung, which in turn not only induces the accumulation of ILC2s in the lung but also stimulates them to produce IL-5 and IL-13, which in combination induce pulmonary eosinophilia. 


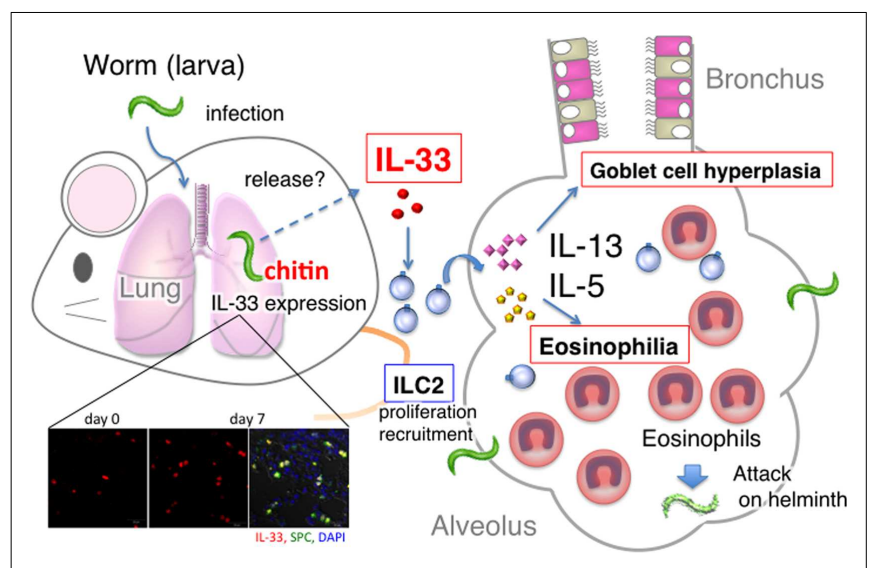

FIGURE 1 | Summary of host protective pulmonary eosinophilia

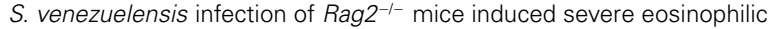
inflammation, goblet cell hyperplasia, and accumulation of ILC2, and increased the number of IL-33 producing type II alveolar epithelial (ATII) cells. First, IL-33 from ATII cells induced and activated ILC2 to produce IL-5 and IL-13. Then, IL-5 and IL-13 in combination induced severe pulmonary eosinophilia. And, perhaps, these eosinophils, increase their capacity to kill helminth after stimulation with IL-33.

\section{S. VENEZUELENSIS INFECTION FAILED TO INDUCE LUNG EOSINOPHILIA IN IL33--- MICE}

Wild type (WT) C57BL/6 mice, infected with S. venezuelensis, developed pulmonary eosinophilia and lung goblet cell hyperplasia at days 5 and 7 after infection. In contrast, S. venezuelensis infected IL-33 $3^{-1-}$ mice failed to develop these changes. These results strongly indicated that $S$. venezuelensis infection induced lung eosinophilic infiltration and goblet cell hyperplasia by induction of IL-33. Therefore, we next tried to determine what type of cells express IL-33. We detected IL-33-expressing cells even before infection. Their number increased and peaked at day 7 . We could determine these IL-33-expressing cells as type II alveolar epithelial (ATII) cells, because they are positive for ATII cell marker ProSurfactant protein C (Figure 1). Other investigators also reported that influenza virus infection induces IL-33 expression in alveolar epithelial and endothelial cells (20). Influenza virus infection also induces IL-33 expression in the alveolar macrophages (21). However, we could not detect IL-33 expression in $\mathrm{F} 4.80^{+}$macrophages in the lungs, suggesting selective activation of ATII cells by $S$. venezuelensis.

\section{INTRANASAL ADMINISTRATION OF CHITIN INDUCES IL-33 IN THE LUNG}

Chitin is a component of the outer membrane of parasites (22), and intranasal administration of chitin beads induces eosinophilic accumulation in the lungs by the action of macrophage and leukotriene $\mathrm{B}_{4}$ (23). Thus, we speculated $S$. venezuelensis infection induced pulmonary eosinophila by the action of chitin. We administered chitin into WT mice and IL- $33^{-/-}$mice, and found that this treatment increased the number of IL-33-expressing ATII cells and IL-33 protein level in the BALF of WT mice. Expectedly, only WT mice developed pulmonary eosinophilia after chitin treatment, suggesting that $S$. venezuelensis infection induces pulmonary eosinophilia at least by the action of chitin to induce an increase in the number of IL-33-expressing ATII cells.

\section{INDUCTION OF ILC2 IN THE LUNGS BY S. VENEZUELENSIS INFECTION}

We next examined whether $S$. venezuelensis infection induces pulmonary eosinophilia without help from Th2 cells. Thus, we infected WT and Rag2 $2^{-I-}$ mice with S. venezuelensis. Both types of mice after infection almost equally increased the number of IL-33expressing ATII cells and developed lung eosinophilia, indicating that acquired immune cells are dispensable for IL-33-induced eosinophil accumulation in the lungs. IL-33 is a potent inducer of IL-5 and IL-13, which are strongly related with the accumulation of eosinophils (24). Th2 cell is a candidate for the source of these cytokines, however, as we showed previously (10), intranasal administration of IL-33 induces pulmonary eosinophilia even in Rag2 ${ }^{-l-}$ mice, excluding contribution of Th2 cells to lung eosinophilic inflammation. ILC2 is another candidate for Th2 cytokine-producing cell in response to IL-33 (25). Therefore, we examined whether $S$. venezuelensis infection induced ILC2s in the lung. We found that $S$. venezuelensis infection induced ILC2s in the lungs of Rag2 ${ }^{-/-}$mice. ILC2s in the BALF started to increase at least at day 7 and increased even beyond day 10 . Compared to WT mice, ST2 deficient mice showed little induction of ILC2s. IL-33 $33^{-1}$ mice also showed very modest increase of ILC2s. And, administration of IL-33 strikingly increased this proportion $(11,26)$.

\section{PULMONARY EOSINOPHILA IS INVOLVED IN HOST DEFENSE AGAINST S. VENEZUELENSIS INFECTION}

Consistent with the above results, IL-33-1- mice developed modest eosinophilia in their lungs, but they became to develop severe pulmonary eosinophilia after IL-33 treatment. Thus, we examined the contribution of IL-33-induced eosinophilia to worm expulsion. We measured their egg deposition. Compared to IL$33^{-1-}$ mice, WT mice significantly reduced their egg deposition at day 8. Importantly, IL- $33^{-1-}$ mice could reduce their egg deposition in response to IL-33 treatment. Interestingly, they more rapidly reduced egg deposition than PBS-treated WT mice. These results are consistent with previous reports that eosinophils are required for the rapid expulsion of larvae, which is demonstrated by anti-IL- $5 \mathrm{Ab}$-treated mice and IL-5 transgenic mice $(27,28)$. The importance of eosinophils in nematode protection was also suggested by a functional study of leukotriene B4 in S. venezuelensis infected mice. Numbers of adult worms and eggs/g/feces were greater in 5-lipoxygenase ${ }^{-/-}$mice or in WT mice treated with leukotriene synthesis inhibitor (MK886) than that in their WT control mice or in PBS-treated WT mice, respectively (29).

Taken together, worms induced IL-33 in the lung by the action of chitin. IL-33 from ATII cells induces and activates ILC2s to produce IL-5 and IL-13, which in combination induce pulmonary eosinophilia and possibly kill helminth (Figure 1). Thus, ILC2s in the lung play an important role in host defense against helminth.

\section{DOES IgE ACT IN CONCERT WITH IgG TO EXPEL $S$. VENEZUELENSIS?}

Th2 cells induced goblet cell hyperplasia and smooth muscle contraction are essential for rapid expulsion of $N$. brasiliensis $(1,2)$. 
However, B cells and antibodies are not required for this expulsion (3). In contrast, Ab-dependent MMC activation is essential for rapid expulsion of $S$. venezuelensis from intestine (8). Thus, host deploys a subset of immune response to expel intestinal nematode, which differs depending on the nature of helminth. As Th2 cells induce various immune responses (e.g., goblet cell hyperplasia, intestinal mastocytosis, local and systemic eosinophilia, and high production of IgG1 and IgE) in mice infected with intestinal nematodes, we tried to determine which components of Th2 immune responses are essentially required for rapid expulsion of S. venezuelensis. Thus, in the last part of this review, we show the importance of acquired immunity for rapid expulsion of $S$. venezuelensis from intestine.

\section{RELEVANCE OF INTESTINAL MASTOCYTOSIS AND AbS AGAINST MURINE STRONGYLOIDIASIS}

The relevance of intestinal mastocytosis has been well documented in the host defense against murine Strongyloidiasis $(5-7,30)$. We previously reported that administration of IL-18 induces intestinal mastocytosis and such IL-18-pretreated mice gain the capacity to strongly expel implanted adult worms (7). We further demonstrated that identically pretreated mast cell-deficient WBB6F1$\mathrm{W} / \mathrm{W}^{\mathrm{v}}$ failed to acquire this capacity. These results strongly indicate that intestinal mastocytosis is required for rapid expulsion of S. venezuelensis (7). However, other investigators suggested that induction of intestinal mastocytosis is not sufficient and that FcR $\gamma$-induced MMC activation is essentially required for rapid expulsion of $S$. venezuelensis (8). Abraham's group demonstrated the contribution of Abs (IgM and IgG) and complement to the protection of mice against larval infection with S. stercoralis (31, 32 ). But, because human pathogen $S$. stercoralis can not grow into adult worms in the mice, the role of Abs against adult worms have not been examined in detail.

\section{AID ${ }^{-/-}$MICE DEVELOP Th2 CELLS BUT LACK THE CAPACITY}

\section{TO EXPEL $S$. VENEZUELENSIS}

To solve these issues, we employed activation-induced cytidine deaminase (AID)-deficient mice devoid of Ig class switching (33). $\mathrm{AID}^{-/-}$mice produce more IgM than do WT mice, but lack IgA, IgG, and IgE (34). Although WT mice showed strong production of IgG1 and IgE following S. venezuelensis infection, $\mathrm{AID}^{-1-}$ mice were unable to produce IgG1 and IgE. WT mice completed expulsion of $S$. venezuelensis by day 12 , whereas $\mathrm{AID}^{-1-}$ mice required additional 9 days to do so. IL-4 production in vivo, which was detected by the in vivo cytokine capture assay (35), did not differ between WT mice and $\mathrm{AID}^{-1-}$ mice at day 10 after infection. Adult worms of S. venezuelensis found in the small intestines of $\mathrm{AID}^{-1-}$ mice outnumbered those of WT mice at day 10 after infection. In contrast, like WT mice, $\mathrm{AID}^{-/-}$mice completed expulsion of $N$. brasiliensis by day 10 after infection, excluding contribution of IgG1 and IgE for expulsion of $N$. brasiliensis. The accumulations of mast cells in $\mathrm{AID}^{-/-}$intestines outnumbered those in WT controls at day 14 after infection. AID $^{-1-}$ mice also produced comparable levels of mouse mast cell protease-1 (mMCP-1) to those by WT mice at day 10 after infection, and produced twice as much as did WT mice at day 14 after infection. These data indicated that although Th2-type immune responses and MMC proliferation occurred normally in $\mathrm{AID}^{-/-}$mice, worm expulsion was retarded compared to WT mice due to their no production of class-switched antibodies.

\section{FCRy-INDUCED MMC ACTIVATION IS ESSENTIALLY REQUIRED FOR RAPID EXPULSION OF S. VENEZUELENSIS}

Thus, we investigated the capacity of immune sera from mice infected with $S$. venezuelensis. $\mathrm{AID}^{-1-}$ mice transferred with S. venezuelensis-immune sera diminished egg deposition in the feces at day 11, which was 11 days earlier than the normal
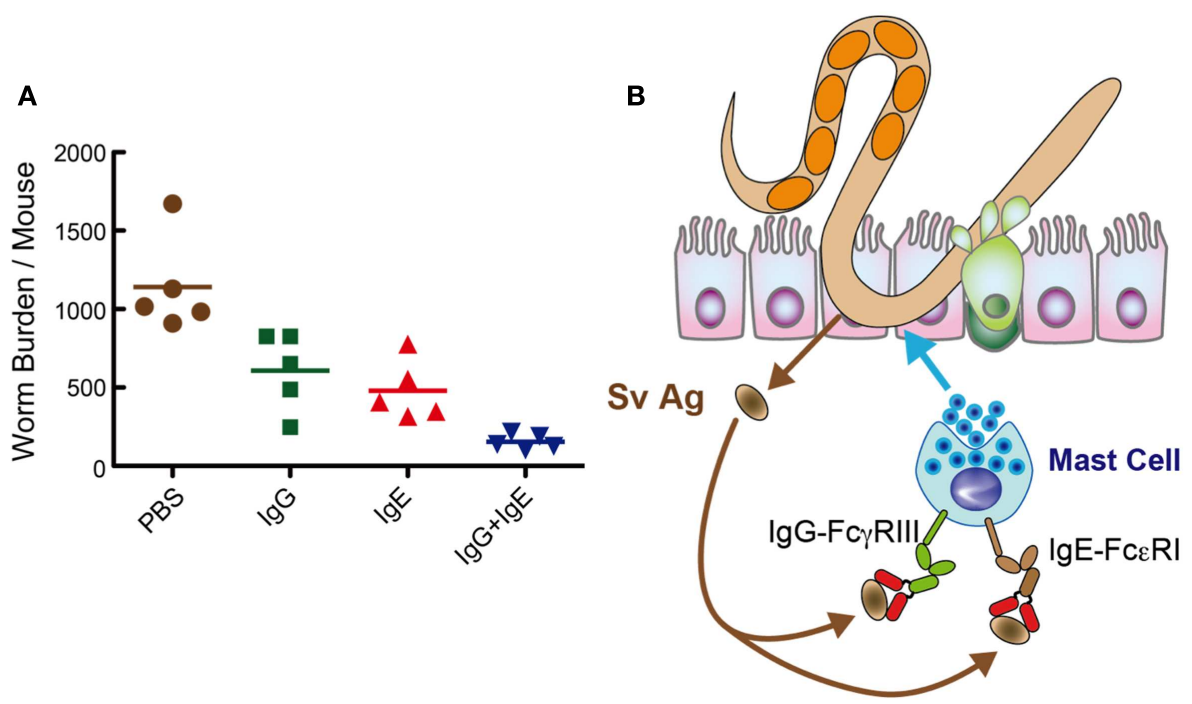

FIGURE 2 | IgG and IgE collaboratively accelerate expulsion of $\boldsymbol{S}$. venezuelensis infection. (A) To examine which classes of Igs are able to induce worm expulsion. We injected $\lg \mathrm{Fr}(1.8 \mathrm{mg})$, IgE Fr $(5 \mu \mathrm{g})$, or a mixture of $\operatorname{lgG} \mathrm{Fr}(1.8 \mathrm{mg})$ and $\operatorname{lgE} \operatorname{Fr}(5 \mu \mathrm{g})$ into $\mathrm{AID}^{-/-}$mice on day 7 after infection with 4,000 L3, and adult worms were recovered at day 8 . As shown here, IgG and $\mathrm{IgE}$ reduced worm burdens collaboratively. (B) Hypothetical mechanism of IgG-and IgE-mediated worm expulsion. 
sera-treated $\mathrm{AID}^{-1-}$ mice. Consistently, $\mathrm{AID}^{-1-}$ mice transferred with $S$. venezuelensis-immune sera almost completely expelled worms. These effects were due to expulsion of adult worms from the small intestines, but not due to the suppression of fecundity. Because N. brasiliensis-immune sera exerted no activities of eliciting worm expulsion, specific Abs against S. venezuelensis could play essential roles in expelling worms from the small intestine. Immune sera-derived IgG and IgE induced worm expulsion via $\mathrm{F} c \gamma$ receptor III $(\mathrm{Fc} \gamma \mathrm{RIII})$ and $\mathrm{Fc} \varepsilon$ receptor I (FceRI), respectively. Although Fc $\gamma \mathrm{RIII}^{-1-}$ mice or FceRI ${ }^{-1-}$ mice could normally expel S. venezuelensis, $\mathrm{F}_{\mathrm{C}} \mathrm{RIII} I^{-1-}$ mice, when their IgE was neutralized by anti-IgE, or Fc\&RI $\alpha^{-1-}$ mice, when their IgGbinding to Fc $\gamma$ RIII was blocked by anti-Fc $\gamma$ RIII, showed markedly reduced ability to expel S. venezuelensis. Additionally, combined administration of IgG and IgE showed a collaborative effect on $S$. venezuelensis expulsion (Figure 2A). These data revealed that IgG and IgE played redundant roles but acted in concert to accelerate $S$. venezuelensis expulsion. IgG or IgE was not able to promote worm expulsion in mast cell-deficient $\mathrm{WBB} 6 \mathrm{~F} 1-\mathrm{W} / \mathrm{W}^{\mathrm{V}}$ mice, indicating that mast cells are cellular targets of IgG and IgE.

In summary, S. venezuelensis infection induced $\operatorname{IgG}$ and $\operatorname{IgE}$ activate Fc $\gamma$ RIII and FceRI, respectively, expressed on mast cells. Then, mast cells get fully activated and expel $S$. venezuelensis promptly from the small intestine (Figure 2B). Recently, El-Malky et al. also reported the importance of B cells in immunity against surgically transferred adult worms of $S$. venezuelensis using B cell-deficient JHD mice (36).

In this review, we showed that acquired lymphoid cells, exemplified by Th 2 cells and B cells and innate lymphoid cells, exemplified by ILC2s, are important for rapid expulsion of intestinal nematode. First, IL-33-induced ILC2s induce pulmonary eosinophilia (Loeffler syndrome), which is the lung-based first defense line for S. venezuelensis. Second, Th2 cells induce intestinal mastocytosis and $\mathrm{Ab}$ production by $\mathrm{B}$ cells (e.g., IgG and $\mathrm{IgE}$ ), which in combination build up the second defense line based on IgG1 plus IgE-mediated MMC activation in the small intestine.

\section{REFERENCES}

1. Finkelman FD, Shea-Donohue T, Morris SC, Gildea L, Strait R, Madden KB, et al. Interleukin-4- and interleukin-13-mediated host protection against intestinal nematode parasites. Immunol Rev (2004) 201:139-55. doi:10.1111/j.0105-2896. 2004.00192.x

2. Hasnain SZ, Evans CM, Roy M, Gallagher AL, Kindrachuk KN, Barron L, et al. Muc5ac: a critical component mediating the rejection of enteric nematodes. J Exp Med (2011) 208:893-900. doi:10.1084/jem.20102057

3. Liu Q, Kreider T, Bowdridge S, Liu Z, Song Y, Gaydo AG, et al. B cells have distinct roles in host protection against different nematode parasites. J Immunol (2010) 184:5213-23. doi:10.4049/jimmunol.0902879

4. Sato Y, Toma H. Strongyloides venezuelensis infection in mice. Int J Parasitol (1990) 20:57-62. doi:10.1016/0020-7519(90)90173-K

5. Khan AI, Horii Y, Tiuria R, Sato Y, Nawa Y. Mucosal mast cells and the expulsive mechanisms of mice against Strongyloides venezuelensis. Int J Parasitol (1993) 23:551-5. doi:10.1016/0020-7519(93)90159-V

6. Maruyama H, Yabu Y, Yoshida A, Nawa Y, Ohta N. A role of mast cell glycosaminoglycans for the immunological expulsion of intestinal nematode, Strongyloides venezuelensis. J Immunol (2000) 164:3749-54.

7. Sasaki Y, Yoshimoto T, Maruyama H, Tegoshi T, Ohta N, Arizono N, et al. IL18 with IL-2 protects against Strongyloides venezuelensis infection by activating mucosal mast cell-dependent type 2 innate immunity. J Exp Med (2005) 202:607-16. doi:10.1084/jem.20042202
8. Onah DN, Uchiyama F, Nagakui Y, Ono M, Takai T, Nawa Y. Mucosal defense against gastrointestinal nematodes: responses of mucosal mast cells and mouse mast cell protease 1 during primary Strongyloides venezuelensis infection in FcR gamma-knockout mice. Infect Immun (2000) 68:4968-71. doi:10.1128/IAI.68. 9.4968-4971.2000

9. Chitkara RK, Krishna G. Parasitic pulmonary eosinophilia. Semin Respir Crit Care Med (2006) 27:171-84. doi:10.1055/s-2006-939520

10. Kondo Y, Yoshimoto T, Yasuda K, Futatsugi-Yumikura S, Morimoto M, Hayashi $\mathrm{N}$, et al. Administration of IL-33 induces airway hyperresponsiveness and goblet cell hyperplasia in the lungs in the absence of adaptive immune system. Int Immunol (2008) 20:791-800. doi:10.1093/intimm/dxn037

11. Yasuda K, Muto T, Kawagoe T, Matsumoto M, Sasaki Y, Matsushita K, et al. Contribution of IL-33-activated type II innate lymphoid cells to pulmonary eosinophilia in intestinal nematode-infected mice. Proc Natl Acad Sci U S A (2012) 109:3451-6. doi:10.1073/pnas.1201042109

12. Schmitz J, Owyang A, Oldham E, Song Y, Murphy E, McClanahan TK, et al. IL-33, an interleukin-1-like cytokine that signals via the IL-1 receptor-related protein ST2 and induces T helper type 2-associated cytokines. Immunity (2005) 23:479-90. doi:10.1016/j.immuni.2005.09.015

13. Baekkevold ES, Roussigné M, Yamanaka T, Johansen FE, Jahnsen FL, Amalric F, et al. Molecular characterization of NF-HEV, a nuclear factor preferentially expressed in human high endothelial venules. Am J Pathol (2003) 163:69-79. doi:10.1016/S0002-9440(10)63631-0

14. Cayrol C, Girard JP. The IL-1-like cytokine IL-33 is inactivated after maturation by caspase-1. Proc Natl Acad Sci U S A (2009) 106:9021-6. doi:10.1073/pnas. 0812690106

15. Hoshino K, Kashiwamura S, Kuribayashi K, Kodama T, Tsujimura T, Nakanishi $\mathrm{K}$, et al. The absence of interleukin 1 receptor-related T1/ST2 does not affect T helper cell type 2 development and its effector function. J Exp Med (1999) 190:1541-8. doi:10.1084/jem.190.10.1541

16. Ho LH, Ohno T, Oboki K, Kajiwara N, Suto H, Iikura M, et al. IL-33 induces IL13 production by mouse mast cells independently of IgE-Fc epsilon RI signals. J Leukoc Biol (2007) 82:1481-90. doi:10.1189/jlb.0407200

17. Matsuba-Kitamura S, Yoshimoto T, Yasuda K, Futatsugi-Yumikura S, Taki Y, Muto T, et al. Contribution of IL-33 to induction and augmentation of experimental allergic conjunctivitis. Int Immunol (2010) 22:479-89. doi:10.1093/ intimm/dxq035

18. Moro K, Yamada T, Tanabe M, Takeuchi T, Ikawa T, Kawamoto H, et al. Innate production of $\mathrm{T}(\mathrm{H}) 2$ cytokines by adipose tissue-associated c-Kit $(+) \mathrm{Sca}-1(+)$ lymphoid cells. Nature (2010) 463:540-4. doi:10.1038/nature08636

19. Mirchandani AS, Salmond RJ, Liew FY. Interleukin-33 and the function of innate lymphoid cells. Trends Immunol (2012) 33:389-96. doi:10.1016/j.it.2012.04.005

20. Le Goffic R, Arshad MI, Rauch M, L'Helgoualc'h A, Delmas B, Piquet-Pellorce C, et al. Infection with influenza virus induces IL-33 in murine lungs. Am J Respir Cell Mol Biol (2011) 45:1125-32. doi:10.1165/rcmb.2010-0516OC

21. Chang YJ, Kim HY, Albacker LA, Baumgarth N, McKenzie AN, Smith DE, et al. Innate lymphoid cells mediate influenza-induced airway hyper-reactivity independently of adaptive immunity. Nat Immunol (2011) 12:631-8. doi:10.1038/ ni.2045

22. Bowman SM, Free SJ. The structure and synthesis of the fungal cell wall. Bioessays (2006) 28:799-808. doi:10.1002/bies.20441

23. Reese TA, Liang HE, Tager AM, Luster AD, Van Rooijen N, Voehringer D, et al. Chitin induces accumulation in tissue of innate immune cells associated with allergy. Nature (2007) 447:92-6. doi:10.1038/nature05746

24. Foster PS, Mould AW, Yang M, Mackenzie J, Mattes J, Hogan SP, et al. Elemental signals regulating eosinophil accumulation in the lung. Immunol Rev (2001) 179:173-81. doi:10.1034/j.1600-065X.2001.790117.x

25. Spits H, Artis D, Colonna M, Diefenbach A, Di Santo JP, Eberl G, et al. Innate lymphoid cells - a proposal for uniform nomenclature. Nat Rev Immunol (2013) 13:145-9. doi:10.1038/nri3365

26. Kim HY, Chang YJ, Subramanian S, Lee HH, Albacker LA, Matangkasombut P, et al. Innate lymphoid cells responding to IL-33 mediate airway hyperreactivity independently of adaptive immunity. JAllergy Clin Immunol (2012) 129:216-27. doi:10.1016/j.jaci.2011.10.036

27. Korenaga M, Hitoshi Y, Takatsu K, Tada I. Regulatory effect of anti-interleukin5 monoclonal antibody on intestinal worm burden in a primary infection with Strongyloides venezuelensis in mice. Int J Parasitol (1994) 24:951-7. doi:10.1016/0020-7519(94)90159-7 
28. El-Malky M, Maruyama H, Hirabayashi Y, Shimada S, Yoshida A, Amano T, et al. Intraepithelial infiltration of eosinophils and their contribution to the elimination of adult intestinal nematode, Strongyloides venezuelensis in mice. Parasitol Int (2003) 52:71-9. doi:10.1016/S1383-5769(02)00086-7

29. Machado ER, Ueta MT, Lourenço EV, Anibal FF, Sorgi CA, Soares EG, et al. Leukotrienes play a role in the control of parasite burden in murine strongyloidiasis. J Immunol (2005) 175:3892-9.

30. Lantz CS, Boesiger J, Song CH, Mach N, Kobayashi T, Mulligan RC, et al. Role for interleukin-3 in mast-cell and basophil development and in immunity to parasites. Nature (1998) 392:90-3. doi:10.1038/32190

31. Brigandi RA, Rotman HL, Yutanawiboonchai W, Leon O, Nolan TJ, Schad GA, et al. Strongyloides stercoralis: role of antibody and complement in immunity to the third stage of larvae in BALB/cByJ mice. Exp Parasitol (1996) 82:279-89. doi:10.1006/expr.1996.0035

32. Ligas JA, Kerepesi LA, Galioto AM, Lustigman S, Nolan TJ, Schad GA, et al. Specificity and mechanism of immunoglobulin M (IgM)- and IgG-dependent protective immunity to larval Strongyloides stercoralis in mice. Infect Immun (2003) 71:6835-43. doi:10.1128/IAI.71.12.6835-6843.2003

33. Matsumoto M, Sasaki Y, Yasuda K, Takai T, Muramatsu M, Yoshimoto T, et al. IgG and IgE collaboratively accelerate expulsion of Strongyloides venezuelensis in a primary infection. Infect Immun (2013) 81:2518-27. doi:10.1128/IAI.00285-13

34. Muramatsu M, Kinoshita K, Fagarasan S, Yamada S, Shinkai Y, Honjo T. Class switch recombination and hypermutation require activation-induced cytidine deaminase (AID), a potential RNA editing enzyme. Cell (2000) 102:553-63. doi:10.1016/S0092-8674(00)00078-7
35. Finkelman FD, Morris SC. Development of an assay to measure in vivo cytokine production in the mouse. Int Immunol (1999) 11:1811-8. doi:10.1093/intimm/ 11.11.1811

36. El-Malky MA, Maruyama H, Al-Harthi SA, El-Beshbishi SN, Ohta N. The role of B-cells in immunity against adult Strongyloides venezuelensis. Parasit Vectors (2013) 6:148. doi:10.1186/1756-3305-6-148

Conflict of Interest Statement: The authors declare that the research was conducted in the absence of any commercial or financial relationships that could be construed as a potential conflict of interest.

Received: 08 November 2013; accepted: 05 March 2014; published online: 19 March 2014.

Citation: Yasuda K, Matsumoto $M$ and Nakanishi K (2014) Importance of both innate immunity and acquired immunity for rapid expulsion of S. venezuelensis. Front. Immunol. 5:118. doi: 10.3389/fimmu.2014.00118

This article was submitted to Microbial Immunology, a section of the journal Frontiers in Immunology.

Copyright (c) 2014 Yasuda, Matsumoto and Nakanishi. This is an open-access article distributed under the terms of the Creative Commons Attribution License (CC BY). The use, distribution or reproduction in other forums is permitted, provided the original author(s) or licensor are credited and that the original publication in this journal is cited, in accordance with accepted academic practice. No use, distribution or reproduction is permitted which does not comply with these terms. 